\title{
Abstracts and Highlight Papers of the 36th Annual European Society of Regional Anaesthesia \& Pain Therapy (ESRA) Congress 2017: Retraction
}

The Editors of Anaesthesia and Regional Anesthesia and Pain Medicine have been made aware that an abstract was submitted for presentation at the 36th Annual European Society of Regional Anaesthesia and Pain Therapy (ESRA) Congress 2017 and presented at the Annual Congress of the Association of Anaesthetists of Great Britain and Ireland (AAGBI) 2017. As a result, the abstract was published in both Regional Anesthesia and Pain Medicine ${ }^{1}$ and Anaesthesia ${ }^{2}$, but the dual publication was without the knowledge of the authors, ESRA or the AAGBI, or either journal. We apologize for this oversight and the resulting dual publication. The abstract is retracted from Regional Anesthesia and Pain Medicine.

\section{REFERENCES}

1. Bird R, Baxter I. Orthopaedic theatre throughput enhancement based on a mobile block room model - quality improvement project. In: Abstracts and Highlight Papers of the 36th Annual European Society of Regional Anaesthesia \& Pain Therapy (ESRA) Congress 2017. Reg Anesth Pain Med. 2017;42(Supplement 5S): e1-200. Available at: http://journals.lww.com/rapm/Fulltext/2017/09001/Abstracts_and_Highlight_Papers_of_the_36th_Annual.1.aspx (abstract ESRA7-0099, accessed 11/11/2017).

2. Bird R, Baxter I. Orthopaedic theatre throughput enhancement based on a mobile Block Room model. A quality improvement project. In: Abstracts. Anaesthesia. 2017;72(Supplement S4):10-88. Available at: http://onlinelibrary.wiley.com/doi/10.1111/anae.14060/full (abstract 91, accessed 11/11/2017). 